\title{
A Study on Competence Assessment of China's Consulting Enterprises Based on BP Neural Network
}

\author{
Houming FAN, Lihong SHI, Tong ZHAO, Guosong DONG, Pingquan GAO, Hanyu ZHANG \\ Transportation Management School, Dalian Maritime University, Dalian, China
}

\begin{abstract}
With the influx of world well-known management consulting enterprises after China's joining WTO and the weakness of Chinese management consulting enterprises, it has become an urgent issue for the local enterprises on how to survive and develop under such intense competition circumstances. According to competence theory and the characteristics of Chinese management consulting enterprises, this study structures an evaluation index system including 3 steps and 23 specific indexes, and based on BP neural network, the paper puts forward a method which provides a theoretical guidance for management consulting enterprises to evaluate their status in the market and also to seek ways to improve their competence effectively.
\end{abstract}

Keywords: management consultation enterprises, competence evaluation, BP neural networks

\section{1 引言}

管理諮詢是幫助企業和企業家, 通過解決管理和 經營問題, 鑒別和抓住新機會, 強化學習和實施變革 以實現企業目標的一種獨立的、專業性諮詢服務。它 作為加強和改善企業經營管理的重要手段, 已被世界 各國公認。20 世紀 70 年代, 美國全產業的 70\%, 日 本全產業的 50\%在諮詢顧問的幫助下改善經營管理, 取得了很大的成績。 80 年代後期, 歐美管理諮詢業以 每年 20-30\%的速度增長, 到 1995 年全球管理諮詢業 的年收入超過 500 億美元。其影響滲透到政治、經濟 生活的許多領域。目前，世界 500 強的企業中有 50\% 左右的公司擁有自己長期合作的國際著名諮詢公司。 我國的管理諮詢業從 20 世紀 80 年代初起步, 隨著改 革開放的不斷深入, 特別是加入 WTO 以後國外著名 管理諮詢公司紛紛進入我國, 帶動了我國管理諮詢業 的迅速發展, 但與發達國家相比差距很大, 遠遠不能 滿足我國社會主義市場經濟發展的要求[1]。我國管理 諮詢企業自身能力的薄弱以及國外知名諮詢企業不斷 湧入國內市場參與競爭使國內諮詢企業面臨巨大的挑 戰, 如何在激烈的競爭中謀求生存和發展是擺在每一 個國內諮詢企業面前的緊迫課題。因此, 國內管理諮 詢企業要想生存和發展, 就要改變這種傳統的競爭觀 念, 將競爭定位於自身競爭力的開發上, 不迦滿足客 戶需要從而構建企業長期可持續發展能力。

競爭力理論較好地解釋了成功企業長期競爭優勢 存在的原因[2], 為了客觀、科學地評價管理諮詢企業
的競爭力, 觀察管理諮詢企業在激烈的市場競爭中所 處的位置, 探索提高管理諮詢企業市場競爭力的途徑, 需要設計一套科學、完整、能夠全方位反映我國管理 諮詢企業競爭力的指標體系。本文從管理諮詢企業競 爭力識別、評價指標體系的建立出發, 結合我國管理 諮詢企業競爭力的特點和內容, 並在此基礎上提出了 基於 BP 神經網路的管理諮詢企業競爭力評價模型, 希 望能為我國管理諮詢企業的發展提供一些新的思路。

\section{2 我國管理諮詢企業競爭力評價指標體系}

\section{1 管理諮詢企業的特點}

管理諮詢企業是以知識作為資源, 為顧客提供知 識型的服務和智慧型的軟科學產品, 而這一生產過程 是通過擁有這類資源的知識型員工來完成。也就是說, 管理諮詢企業是一種知識型的企業, 與傳統企業的重 要區別在於, 它所提供的產品是知識產品, 它所擁有 的員工是專業知識型人才。管理諮詢企業與傳統企業 的對比見表 1 。

管理諮詢企業應具有以下幾個特點[3]:

1) 適應於團隊工作而不是個人工作。傳統的直線 結構以自上而下的指揮是不能夠適應管理諮詢企業的 發展, 諮詢方案的制定依賴於團隊合作的集體智慧; 2) 適應於專案工作而不是職能性工作。每個諮詢專案 都需要一個跨多個專家部門的專案團隊, 工作方式是 
表 1. 管理諮詢企業與傳統企業的對比

Table 1. Contrast between management consultation enterprises and traditional enterprises

\begin{tabular}{|c|c|c|}
\hline & 管理諮詢企業 & 傳統企業 \\
\hline 重要資源 & 知識、專業人才、聲譽 & 資金、機器設備 \\
\hline 組織結構 & 扁平化、網路化結構 & 等級森嚴的金字塔型結構 \\
\hline 管理關係 & 強調自主性、參與性的柔性管理 & 強調組織性、紀律性的剛性管理 \\
\hline 管理思想 & 開放互動管理, 激勵學習創新 & 統一集中管理, 提倡服從命令 \\
\hline 工作方式 & $\begin{array}{l}\text { 根據任務成立靈活應變的工作團隊, 不 } \\
\text { 同專家部門參與並行工作 }\end{array}$ & $\begin{array}{l}\text { 各職能部門, 各專業部門只是工作流程 } \\
\text { 中獨立的環節 }\end{array}$ \\
\hline 最終產品 & 軟科學方案、知識型服務 & 有形產品 \\
\hline
\end{tabular}

基於專案的專業化合作;

3) 適應于創新而不是重複性的任務。管理諮詢企 業每次面臨的業務都是極具個性化的, 針對不同企業的 問題, 諮詢服務更注重通過創新實現知識的商品化。

\section{2 我國管理諮詢企業競爭力評價指標體系的建立}

企業競爭力的價值取向在於創造更多的財富, 由 企業長期積累的多種要素所構成。關於企業競爭力構
成要素集合問題曾有許多專家學者進行研究, 至今未 知尚無一個比較完善的構成要素體系, 這主要是因為 競爭力理論本身就是一個動態的、發展的理論[4]。

基於邁克爾·波特的價值鏈理論[5]，結合管理諮詢 企業價值創造和經濟效益的特殊性，我們改造了一般 企業的價值活動中各項活動之間的聯繫，形成了管理 諮詢企業的價值鏈示意圖，使其符合管理諮詢企業的 價值創造過程, 如圖 1 所示。

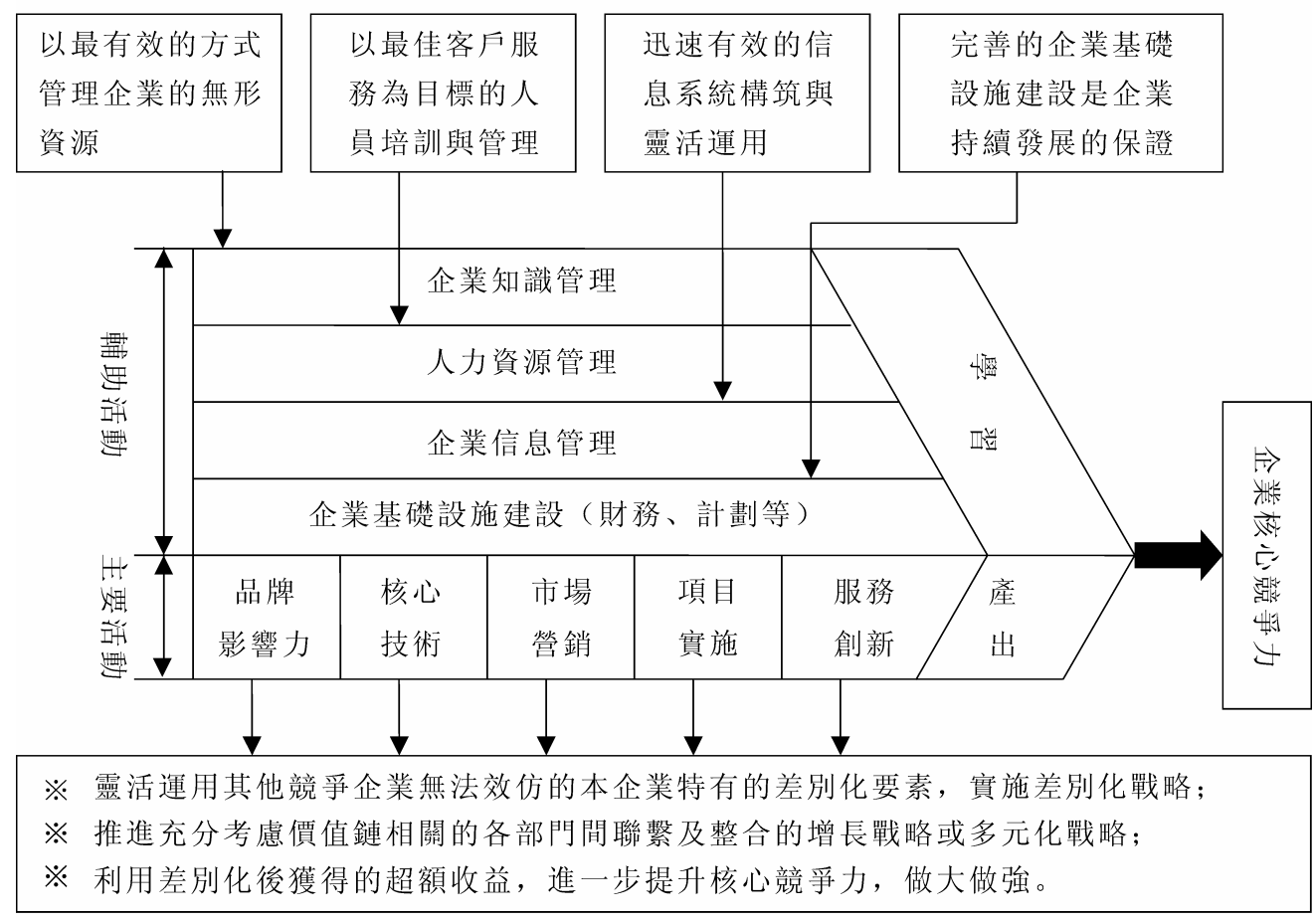

圖 1. 管理諮詢企業價值鏈示意圖

Figure 1. Sketch of value chain in management consultation enterprises 
全面、準確地評價管理諮詢企業競爭力的關鍵在 於構建出完整系統的評價指標體系[6]。本文在前面 對管理諮詢企業競爭力內涵及構成要素分析的基礎 上，按照指標體系設計原則要求，參考了國內外關於
企業競爭力評價指標體系的設計思路，構建出管理諮 詢企業競爭力評價指標體系。從 3 個一級指標、6 個 二級指標、23 個具體評價指標建立了下面的管理諮詢 企業競爭力評價指標體系，如表 2 所示。

表 2. 管理諮詢企業競爭力評價指標體系

Table 2. Evaluation indicator system of competence of management consultation enterprises

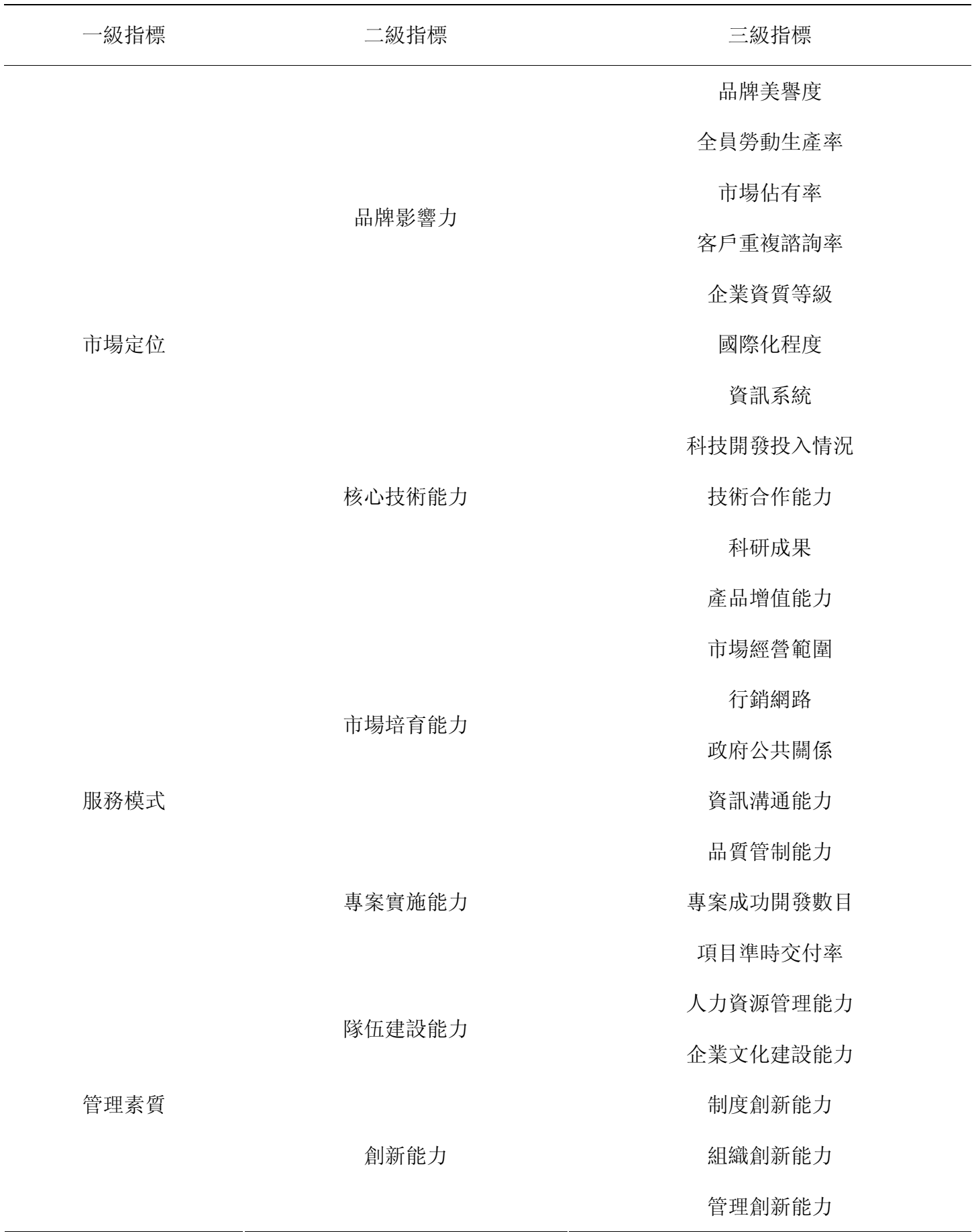


1) 市場定位亦稱產品定位, 是管理諮詢企業提供 的產品的定位, 其中二級指標包括品牌競爭力和核心 技術能力。一個管理諮詢企業品牌的社會影響力主要 包括企業資質等級、企業品牌美譽度、企業國際化程 度、市場佔有率、客戶重複諮詢率、全員勞動生產率。 核心技術能力是企業獲得核心競爭力和專案成功的推 動力, 對管理諮詢企業來說, 核心技術能力是主要的 競爭力, 甚至包括制定標準規範的能力。擁有了技術 制高點, 企業才能有佔領市場的主動權、控制權, 成 為最終戰勝競爭對手的有力保障。

2) 服務模式是管理諮詢企業為了使其產品能夠 佔領更多份額市場所提供的配套措施, 包括市場培育 能力和項目實施能力。市場培育能力主要指開拓和行 銷能力, 開拓能力是指研究開發市場、擴大市場, 提 高企業的市場佔有率。市場行銷能力直接決定了企業 能否將技術優勢外化為市場競爭優勢。管理諮詢企業 必須具有與專案的規模相匹配的管理技能。管理諮詢 企業必須安排適當的人力資源、調整進度計畫並保證 工作以最合適的方式進行規劃。

3) 管理素質。主要包括隊伍建設能力和創新能 力。“人”是構成服務型企業的重要組成部分, 是知識 來源和不斷學習進步的主體, 因此加強團隊建設、培 養職業道德觀念是管理諮詢企業所必須嚴肅對待的問 題。創新是腪固市場的籌碼, 它能夠提供給顧客產品 以外的增值服務。

\section{3 基於 BP 神經網路的我國管理諮詢企業競 爭力評價模型}

進行評價時, 通常所採用的方法在實施過程中必 須假設變數之間是線性關係, 變數之間不存在相互影 響。而根據前面的研究, 我們發現管理諮詢企業的競 爭力是由一個複雜的系統構成, 評價目標與評價指標 之間還存在著隱藏層, 並且系統間各影響因素存在非 線性關係, 同時許多指標不能用數值確定, 即沒有明 確邊界、只有評價程度的高低。所以在對管理諮詢企 業競爭力評價指標進行資訊處理時, 我們選用了人工 神經網路法 (ANN)。人工神經網路法結構簡單, 兼 顧了網路訓練的快速性和運算的精確性, 避免了所研 究問題內部規律的複雜描述; 演算法穩定性較好, 容 錯性自適應性強, 具有聯想記憶功能, 適宜處理資訊 不完整的資料。因此, 本文構建的 BP 神經網路評價 模型, 為我國管理諮詢企業競爭力的評價提供了一條 新的途徑。

\subsection{BP 神經網路原理}

BP (Back Propagation) 演算法稱為誤差反傳演算 法, 從結構上來講, 它是一種分層型網路, 具有輸入 層、中間層 (隱層)、輸出層。網路層除輸入輸出節點 外, 還有一層或多層隱層節點, 同層節點中沒有任何 耦合。輸入信號從輸入層節點依次傳過各層隱層節點,

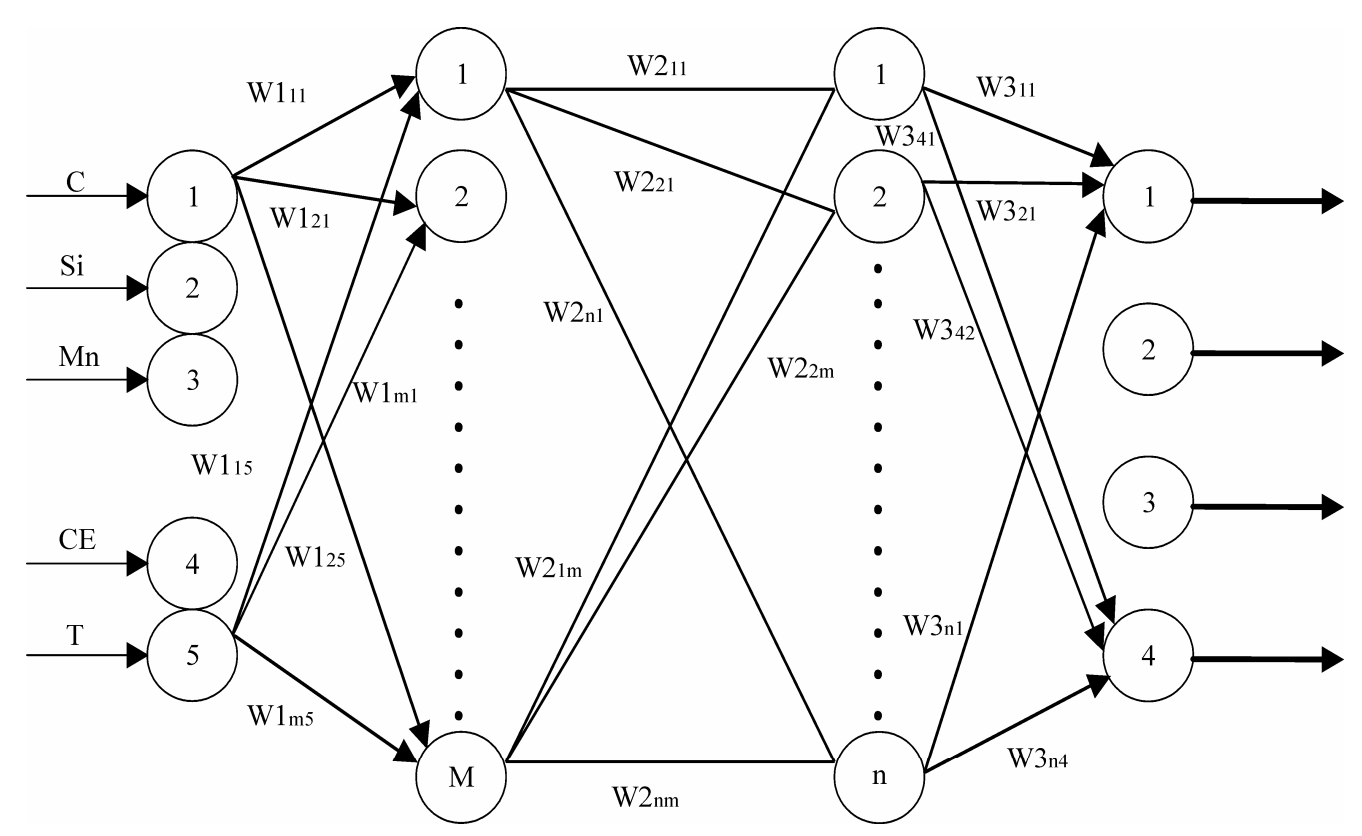

圖 2. BP 演算法多層前饋型網路結構圖

Figure 2. The structure of feed-forward networks of BP algorithm 
然後傳到輸出節點, 每一層節點的輸出只影響下一層 節點的輸出[7]。基於 BP 演算法的多層前饋型網路的 結構見圖 2 所示[8]。

這種網路不僅有輸入節點、輸出節點, 而且還有 一層或多層隱含節點。對於輸入資訊, 要先向前傳播 到隱層的節點上, 經過各單元的特性為 Sigmoid 型的 啟動函數（又稱作用函數、轉換函數或影射函數）運 算後, 把隱含節點的輸出資訊傳播到輸出節點, 最後 給出輸出結果。網路學習過程由正向和反向傳播兩部 分組成。在正向傳播過程中, 每一層神經元的狀態只 影響到下一層神經元網路。如果輸出層不能得到期望 輸出, 就是實際輸出值與期望輸出值之間有誤差, 那 麼轉入反向傳播過程, 將誤差信號沿原來的連接通路 返回, 通過修改各層神經元的權值, 逐次地向輸入層 傳播去進行計算, 再經過正向傳播過程, 這兩個過程 的反復運用, 使得誤差信號最小。實際上, 誤差達到 人們所希望的要求時, 網路的學習過程就結束。BP 神經網路計算流程圖如圖 3 所示[9]。

\section{2 基於 BP 神經網路的評價模型結構設計}

1) 輸入節點的確定及輸入資料的處理

管理諮詢企業競爭力評價模型的網路輸入應為第 四章的評價指標體系中各指標要素。由前文可知, 指 標共 23 項, 因此 BP 神經網路模型的輸入節點為 23 個。

模型輸入資料的預處理是模型建立伊始就要解決 的一個重要問題, 是研究物件與網路模型的介面。由 於評價指標體系中, 既有定性指標又有定量指標, 為 使各指標在整個系統中具有可比性，必須對各指標進 行標準化處理。

(1) 定量指標的處理

對於定量指標，因其衡量單位不同，級差有大 有小, 須對其進行規範化和同趨化處理。雖然在指 標體系中存在兩種類型的定量指標：正指標和逆指 標, 正指標要求數值越大越好, 逆指標則要求數值 越小越好, 但考慮到本文所建立的管理諮詢企業競

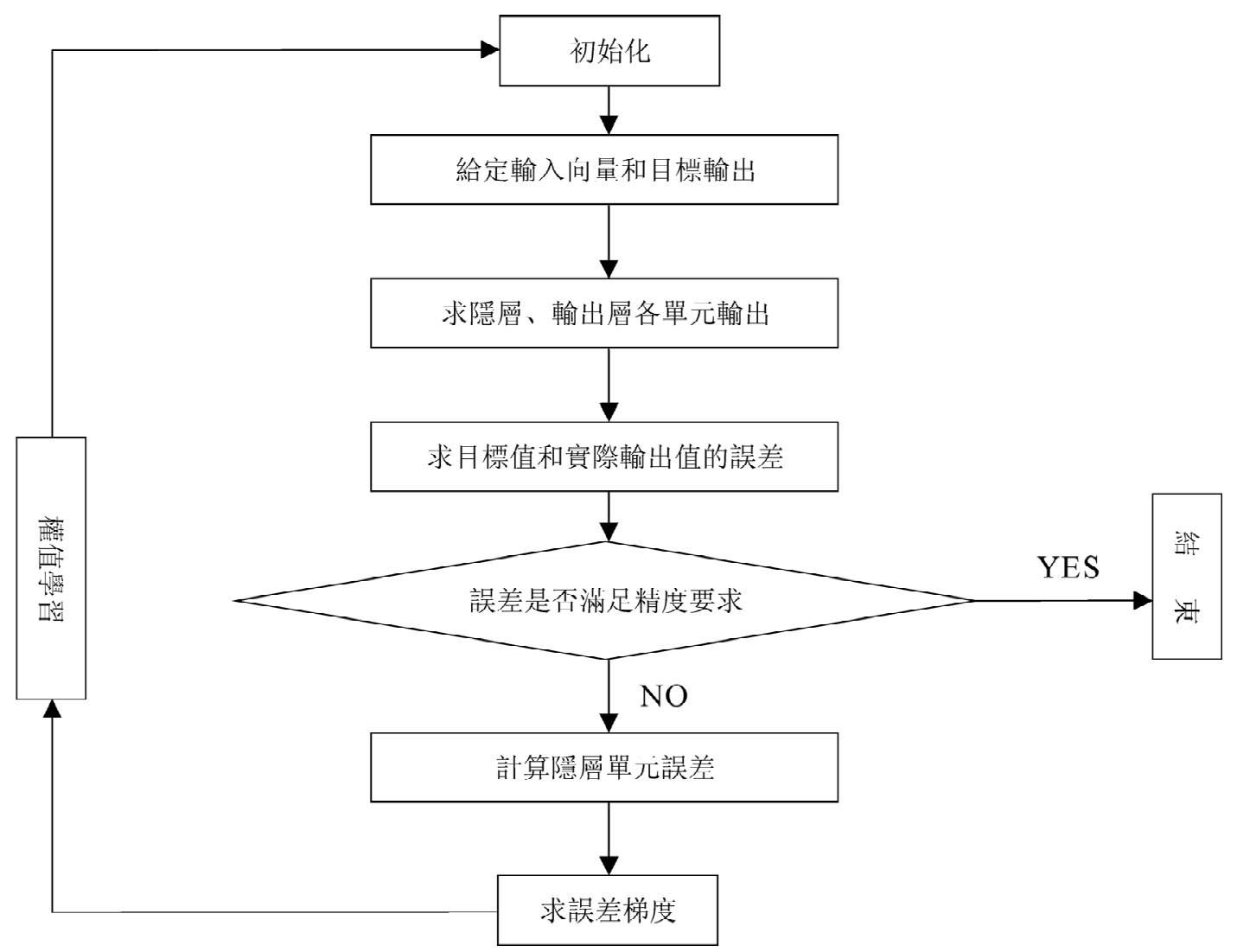

图 3. BP 神经网络计算流程图

Figure 3. Computing flow chart of BP neural networks 
爭力評價指標體系中的評價要素都為正指標, 故處 理公式如 (1) 所示。

(2) 定性指標的處理

對於定性指標, 本文採用 “專家打分法”進行量 化。專家打分法的優點在於方法簡單、易懂、節約時 間。依據慣例, 本文將定性指標的打分為 (1，2，3， 4, 5)五個等級標準, 分別順序對應管理諮詢企業競爭 力指標所達到的程度: (差, 較差, 一般, 較好, 優秀)。 為了保持與定量指標之間的可比性, 必須將其再進行 標準化處理，處理方法與定量指標的處理相同。

定量、定性指標資料標準化處理公式如下:

當目標越大評價越好時:

$$
X_{i o}=\frac{X_{i}-X_{i \min }}{X_{i \max }-X_{i \min }}
$$

其中 $X_{i}$ 為第 $\mathrm{i}$ 個指標數值; $X_{i o}$ 為第 $\mathrm{i}$ 個指標歸 一化後的指標數值; $X_{\text {max }}$ 和 $X_{\text {min }}$ 分別是第 $\mathrm{i}$ 個指標數 值的最大值和最小值。

2) 輸出節點的確定

對企業競爭力的評價是一個從定性到定量然後再 到定性的過程, 通過 BP 網路模型將定性轉化為定量 輸出, 然後綜合評價集和輸出結果, 對企業競爭力作 出定性評價。因此, 將輸出層神經元設置為 1 個。評 價集設為: 好、較好、一般、較差、差五個等級。設 定最高分和最低分, 比如說 0 和 1, 可用如下原則評 價: $x \geqslant 0.9$, 好; $0.7 \leqslant x \leqslant 0.9$, 較好; $0.5 \leqslant x<0.7$, 一般; $0.3 \leqslant x<0.5$, 較差; $x<0.3$, 差。

3) 隱層節點的確定

隱層節點數的確定是一個十分複雜的問題 沒有很 好的解析式表示, 可以說隱層節點數與問題的要求、輸 入輸出單元的多少都有直接的關係。隱層節點數太少, 網路不能訓練出來, 或網路不強壯, 不能識別以前沒有 看到的樣本, 容錯性差; 隱層節點數太多又使學習時間 過長, 誤差也不一定最佳。在長期的應用過程中形成了 一些參考公式[10]。因此結合文中的實際情況, 本文根 據下面的參考公式確定隱層節點的個數。

$$
\mathrm{N}=\sqrt{m+n}+a
$$

其中 $\mathrm{m}$ 為輸出節點數, $\mathrm{n}$ 為輸入節點數, $\mathrm{a}$ 為 1-10 間的常數。本文通過反復測試, 確定的隱層節點數為 10 個。

由此, 本文設計的用於管理諮詢企業競爭力評價 的 BP 神經網路的結構為 23-10-1(即 23 個輸入層神經 元, 10 個隱層神經元, 輸出層只有 1 個神經元)的網 路結構。

\subsection{BP 神經網路的評價程式}

依據 BP 神經網路模型的結構設計, 形成一個 BP 神經網路模型, 對管理諮詢企業競爭力進行評價的步 驟如下[11]:

1) BP 神經網路模型的結構設計;

2）BP 神經網路的學習訓練;

3）搜集評價企業的指標值 $\left\{x_{i}\right\}$;

4) 對 $\left\{x_{i}\right\}$ 進行標準化處理;

5) 將處理過的 $\left\{x_{i}\right\}$ 輸入 BP 神經網路, 按照前 面確定的權重 $w_{j i}$, 計算輸出;

6)根據輸出按評價標準對管理諮詢企業競爭力下 評價結論。

\section{4 實例驗證}

本文在 2007 年具有影響力的《中國管理諮詢機構 100 家名單》中選取上海地區 13 傢俱有代表性的管理 諮詢企業, 其中 10 家調查資料作為 BP 神經網路模型 訓練樣本，3 家（A、B、C 管理諮詢公司）作為評價 物件[12,13]。作為訓練樣本的 10 家企業相關評價指標 的原始資料經過標準化處理後如表 3 所示。

根據已經建立的基於 BP 神經網路的管理諮詢企 業競爭力評價模型可知, 本文採用三層 BP 神經網路, 輸出層神經元節點數即評價指標體系的第三層指標數 為 23, 隱層神經元節點數為 10 , 輸出層神經元節點數 為 1, 該網路的拓撲結構為 23-10-1。

網路輸入層與隱層, 以及隱層和輸入層之間的傳 遞函數分別採用對數 Sigmoid 函數 Logsig()和正切 Sigmoid 函數 Tansig(); 考慮到網路的規模和學習時間, 選用 Traingdx 函數對網路進行訓練; 最大訓練步數 epochs 為 10,000; goal 為 0.0001; show 為 25。其他 參數均為缺省值。

網路經過初始化後, 利用函數 Trainrgdx 對網路進 行 794 次訓練後, 網路誤差平方和 mse 達到了誤差目 標 goal $=0.0001$ 的要求。

網路訓練達到要求後, 可得如表 4 所示的訓練 值。從表 4 可以看出, 原始期望值與神經網路模型的 訓練值非常接近。也就是說, 該模型能較為準確地根 據各評價指標來確定管理諮詢企業競爭力的狀況。因 此, 網路模型訓練結束, 基於 BP 神經網路的管理諮 詢企業競爭力評價模型已經建成。在對其他管理諮詢 企業競爭力進行評價時, 只需輸入評價樣本標準化處 理後的指標資料, 即可得到評價結果。 
BASED ON BP NEURAL NETWORK

表 3. 標準化處理後的學習樣本指標資料

Table 3. Standardized data of evaluation indicators of learning sample

\begin{tabular}{|c|c|c|c|c|c|c|c|c|c|c|c|}
\hline 指 標 & 要素 & 1 & 2 & 3 & 4 & 5 & 6 & 7 & 8 & 9 & 10 \\
\hline \multirow{6}{*}{$\begin{array}{c}\text { 品牌 } \\
\text { 影響 } \\
\text { 力 }\end{array}$} & $x_{11}$ & 0.708 & 0.661 & 0.853 & 0.688 & 0.776 & 0.632 & 0.801 & 0.547 & 0.732 & 0.49 \\
\hline & $x_{12}$ & 0.605 & 0.591 & 0.601 & 0.584 & 0.72 & 0.55 & 0.563 & 0.529 & 0.57 & 0.57 \\
\hline & $x_{13}$ & 0.707 & 0.657 & 0.798 & 0.738 & 0.621 & 0.583 & 0.609 & 0.621 & 0.537 & 0.568 \\
\hline & $x_{14}$ & 0.581 & 0.56 & 0.598 & 0.52 & 0.59 & 0.524 & 0.533 & 0.533 & 0.601 & 0.504 \\
\hline & $x_{15}$ & 0.439 & 0.566 & 0.589 & 0.424 & 0.566 & 0.424 & 0.577 & 0.424 & 0.452 & 0.452 \\
\hline & $x_{16}$ & 0.626 & 0.626 & 0.671 & 0.601 & 0.682 & 0.671 & 0.626 & 0.671 & 0.542 & 0.682 \\
\hline \multirow{5}{*}{$\begin{array}{l}\text { 核心 } \\
\text { 技術 } \\
\text { 能力 }\end{array}$} & $x_{21}$ & 0.49 & 0.453 & 0.769 & 0.671 & 0.613 & 0.692 & 0.792 & 0.803 & 0.688 & 0.683 \\
\hline & $x_{22}$ & 0.456 & 0.561 & 0.512 & 0.447 & 0.436 & 0.57 & 0.393 & 0.347 & 0.503 & 0.372 \\
\hline & $x_{23}$ & 0.551 & 0.68 & 0.692 & 0.692 & 0.813 & 0.577 & 0.708 & 0.512 & 0.844 & 0.68 \\
\hline & $x_{24}$ & 0.702 & 0.479 & 0.668 & 0.491 & 0.581 & 0.683 & 0.465 & 0.702 & 0.442 & 0.668 \\
\hline & $x_{25}$ & 0.651 & 0.642 & 0.673 & 0.45 & 0.642 & 0.575 & 0.683 & 0.568 & 0.591 & 0.406 \\
\hline \multirow{4}{*}{$\begin{array}{l}\text { 市場 } \\
\text { 培育 } \\
\text { 能力 }\end{array}$} & $x_{31}$ & 0.579 & 0.532 & 0.649 & 0.494 & 0.601 & 0.561 & 0.613 & 0.502 & 0.548 & 0.494 \\
\hline & $x_{32}$ & 0.609 & 0.58 & 0.637 & 0.588 & 0.609 & 0.56 & 0.625 & 0.573 & 0.58 & 0.529 \\
\hline & $x_{33}$ & 0.61 & 0.59 & 0.614 & 0.522 & 0.597 & 0.568 & 0.582 & 0.559 & 0.601 & 0.501 \\
\hline & $x_{34}$ & 0.592 & 0.642 & 0.541 & 0.584 & 0.57 & 0.642 & 0.513 & 0.577 & 0.614 & 0.606 \\
\hline \multirow{3}{*}{$\begin{array}{l}\text { 項目 } \\
\text { 實施 } \\
\text { 能力 }\end{array}$} & $x_{41}$ & 0.504 & 0.402 & 0.755 & 0.42 & 0.755 & 0.447 & 0.504 & 0.447 & 0.474 & 0.447 \\
\hline & $x_{42}$ & 0.582 & 0.566 & 0.601 & 0.549 & 0.616 & 0.621 & 0.639 & 0.481 & 0.601 & 0.508 \\
\hline & $x_{43}$ & 0.485 & 0.443 & 0.631 & 0.528 & 0.631 & 0.528 & 0.684 & 0.443 & 0.583 & 0.402 \\
\hline \multirow{3}{*}{$\begin{array}{l}\text { 隊伍 } \\
\text { 建設 } \\
\text { 能力 }\end{array}$} & $x_{51}$ & 0.466 & 0.401 & 0.577 & 0.508 & 0.57 & 0.541 & 0.613 & 0.577 & 0.489 & 0.489 \\
\hline & $x_{52}$ & 0.59 & 0.533 & 0.635 & 0.618 & 0.541 & 0.591 & 0.568 & 0.523 & 0.599 & 0.429 \\
\hline & $x_{61}$ & 0.584 & 0.44 & 0.649 & 0.461 & 0.668 & 0.503 & 0.621 & 0.417 & 0.487 & 0.397 \\
\hline \multirow[t]{2}{*}{$\begin{array}{l}\text { 創新 } \\
\text { 能力 }\end{array}$} & $x_{62}$ & 0.532 & 0.541 & 0.582 & 0.406 & 0.581 & 0.541 & 0.598 & 0.582 & 0.443 & 0.443 \\
\hline & $x_{63}$ & 0.566 & 0.581 & 0.608 & 0.541 & 0.541 & 0.516 & 0.581 & 0.592 & 0.541 & 0.608 \\
\hline \multicolumn{2}{|c|}{ 期望值 } & 0.626 & 0.67 & 0.604 & 0.608 & 0.592 & 0.575 & 0.526 & 0.562 & 0.523 & 0.487 \\
\hline
\end{tabular}


表 4. 原始期望值與神經網路模型的訓練值比較

Table 4. Comparison between original expected value and trained value in BP neural networks model

\begin{tabular}{c|ccccc}
\hline & 1 & 2 & 3 & 4 & 5 \\
\hline 期望值 & 0.626 & 0.67 & 0.604 & 0.608 & 0.592 \\
訓練值 & 0.63294 & 0.66949 & 0.60475 & 0.60457 & 0.58945 \\
\hline & 6 & 7 & 8 & 9 & 10 \\
\hline 期望值 & 0.575 & 0.526 & 0.562 & 0.523 & 0.487 \\
訓練值 & 0.57211 & 0.52598 & 0.5587 & 0.52573 & 0.4894 \\
\hline
\end{tabular}

表 5. 評價企業標準化指標資料

Table 5. Standardized indicator data to evaluate enterprises

\begin{tabular}{|c|c|c|c|c|}
\hline 指標 & 許價要素 & $\mathrm{A}$ 公司 & B 公司 & C 公司 \\
\hline \multirow{6}{*}{ 品牌影葲力 } & 品牌美譽度 & 0.601 & 0.661 & 0.45 \\
\hline & 全員勞動生產率 & 0.584 & 0.605 & 0.541 \\
\hline & 市場佔有率 & 0.707 & 0.483 & 0.517 \\
\hline & 客戶重複諮詢率 & 0.581 & 0.601 & 0.548 \\
\hline & 企業資質等級 & 0.566 & 0.424 & 0.707 \\
\hline & 國際化程度 & 0.64 & 0.492 & 0.56 \\
\hline \multirow{5}{*}{$\begin{array}{c}\text { 核心技術 } \\
\text { 能力 }\end{array}$} & 資訊系統 & 0.771 & 0.49 & 0.408 \\
\hline & 科技開發投入情況 & 0.456 & 0.684 & 0.57 \\
\hline & 技術合作能力 & 0.577 & 0.692 & 0.512 \\
\hline & 科哳成果 & 0.465 & 0.581 & 0.668 \\
\hline & 產品增值能力 & 0.568 & 0.635 & 0.523 \\
\hline \multirow{4}{*}{$\begin{array}{c}\text { 市場培育 } \\
\text { 能力 }\end{array}$} & 市場經營範圍 & 0.646 & 0.551 & 0.529 \\
\hline & 行銷網路 & 0.614 & 0.512 & 0.601 \\
\hline & 政府公共關係 & 0.579 & 0.649 & 0.494 \\
\hline & 資訊溝通能力 & 0.513 & 0.57 & 0.642 \\
\hline \multirow{3}{*}{$\begin{array}{c}\text { 專案實施 } \\
\text { 能力 }\end{array}$} & 品質管制能力 & 0.755 & 0.504 & 0.42 \\
\hline & 專案成功開發數目 & 0.639 & 0.544 & 0.544 \\
\hline & 項目準時交付率 & 0.684 & 0.456 & 0.57 \\
\hline \multirow{2}{*}{$\begin{array}{c}\text { 隊伍建設 } \\
\text { 能力 }\end{array}$} & 人力資源管理能力 & 0.541 & 0.577 & 0.613 \\
\hline & 企業文化建設能力 & 0.575 & 0.683 & 0.45 \\
\hline \multirow{3}{*}{ 創新能力 } & 制度創新能力 & 0.649 & 0.487 & 0.584 \\
\hline & 組織創新能力 & 0.582 & 0.504 & 0.638 \\
\hline & 管理創新能力 & 0.608 & 0.541 & 0.581 \\
\hline
\end{tabular}


現以上海地區同行業, 具有競爭關係的某三家管 理諮詢企業 A、B、C 為例, 它們的企業競爭力的有 關指標資料經過標準化處理後如表 5 所示。

將得到各被評價企業的標準化矩陣:

$a=[0.601 ; 0.584 ; 0.707 ; 0.581 ; 0.566 ; 0.640 ; 0.771 ; 0.45$ $6 ; 0.577 ; 0.465 ; 0.568 ; 0.646 ; 0.614 ; 0.579 ; 0.513 ; 0.755 ; 0.63$ $9 ; 0.684 ; 0.541 ; 0.575 ; 0.649 ; 0.582 ; 0.608]$

$b=[0.661 ; 0.605 ; 0.483 ; 0.601 ; 0.424 ; 0.492 ; 0.490 ; 0.68$ $4 ; 0.692 ; 0.581 ; 0.635 ; 0.551 ; 0.512 ; 0.649 ; 0.570 ; 0.504 ; 0.54$ $4 ; 0.456 ; 0.577 ; 0.683 ; 0.487 ; 0.504 ; 0.541]$

c $=[0.450 ; 0.541 ; 0.517 ; 0.548 ; 0.707 ; 0.560 ; 0.408 ; 0.57$ $0 ; 0.512 ; 0.668 ; 0.523 ; 0.529 ; 0.601 ; 0.494 ; 0.642 ; 0.420 ; 0.54$ $4 ; 0.570 ; 0.613 ; 0.450 ; 0.584 ; 0.638 ; 0.581]$

作為網路輸入向量, 利用訓練好的網路進行仿 真, 分別查看可得仿真結果: a_outputs $=0.65232$ 、 b_outputs $=0.62396 、$ c_outputs $=0.60007$ 。由此可知, A、 B、C 三家企業的競爭力均處於一般水準 $(0.5 \leqslant 0<$ 0.7 , 且企業 $A$ 的競爭能力最強, 其次是企業 $B$, 最 弱的是企業 C。經核對, 評價結果與實際相符。

\section{5 結論}

基於 BP 神經網路的管理諮詢企業競爭力評價問 題的研究主要包括兩個方面, 其一是基於管理諮詢企 業價值鏈的評價指標體系的建立, 其二是基於 BP 神 經網路的評價模型的構建與應用。通過實例研究, 可 以驗證 BP 神經網路法在我國管理諮詢企業競爭力評 價中具有可行性和方便性。基於此, 對於本文的評價 模型構建與實例應用進行以下說明:

1) 用 BP 神經網路進行評價, 對學習樣本的要求 較高, 評價對象越接近, 評價結果越準確。但事實上, 被評價企業的差別往往較大。因此, 期望輸出值可以 用各管理諮詢企業競爭力的模糊綜合評價方法所得結 果進行樣本學習。鑒於本文篇幅有限, 各管理諮詢企 業競爭力的模糊綜合評價過程不再贅述;

2) 本論文所研究的模型是對管理諮詢企業競爭力 的綜合評價, 反應企業競爭力的總體狀況。由於 BP 神經網路演算法完成的是 $\mathrm{n}$ 維輸入空間到 $\mathrm{m}$ 維輸出空 間的非線性映射, 無需事先掌握這種映射關係的數學 方程。因此, 整個 BP 神經網路模型的計算過程都處 於“黑箱子”狀態。本研究所建立的 BP 神經網路評價 模型只能夠得到對於一級評價指標即管理諮詢企業競 爭力的評價結果, 而對於品牌影響力、核心技術能力、
市場開拓和行銷能力、專案交付能力、服務創新能力 五個二級指標, 其分別對應的評價值無法應用此評價 模型得出。

3）BP 神經網路模型的評價精度和科學性不僅取 決於訓練樣本的數量, 也取決於訓練樣本的品質。因 此, 應用中的主要不足在於難以一次得到足夠多的理 想樣本, 這需要在使用過程中逐步積累學習經驗和有 效樣本, 使應用於企業競爭力評價的 BP 神經網路模 型更加完善。

\section{REFERENCES}

[1] 曾慶學. 中國管理諮詢業發展現狀的分析 [J]. 資訊空 間, 2004, (4): 116-122.

[2] 羅志明, 楊炎. 中國管理諮詢企業核心競爭力探析 [J]. 商場現代化, 2008, (1): 97.

[3] 陳建偉. 品牌服裝企業核心競爭力理論及評價體系研 究[D]. 青島: 青島大學, 2006.

[4] 胡大立. 企業核心競爭力的構成要素及其構建 [J]. 科 技進步與對策, 2003, (5): 64-65.

[5] 邁克爾・波特著. 陳小悅譯. 競爭優勢 $[\mathrm{M}]$. 北京：華 夏出版社, 1997. 40-41.

[6] Oliver, C., "Sustainable competitive advantage: Combinning institutional and resouce-based views [J]," Strategic Management Journal, Vol. 18, No. 9, pp. 697-713, 1997.

[7] Patel, Par, Pavit, and Keith. "The technological competencies of the world's largest firm: Complex and Path-dependent,but not much Variety [J]," Research Policy, Vol. 26, pp. 141-156, 1997.

[8] 張青等. 基於神經網路的煤礦企業經營績效評價研究 [J]. 煤炭學報, 2002, (2).

[9] 魏明俠. 基於人工神經網路的綠色行銷績效評價方法 研究 [J]. 科技管理研究, 2003, (2).

[10] Fish, K. E., Johnson, J. D., Dorsey, R. E., and Blodgett, J. G., "Using an artificial neural network trained with a genetic algorithm to model brand share [J]," Journal of Business Research, Vol. 57, No. 1, pp. 79-85, 2004.

[11] 聶辰席. 基於神經網路的企業競爭力綜合評價方法 [D]. 天津: 天津大學, 2007.

[12] http://tbbs.techcn.com.cn/156038.html.

[13] http://www.topo100.com/qygl/zzjg/2006-09-07/1339.html. 